\title{
A cross-sectional study of associations between herd-level calf mortality rates, compliance with legislation on calf welfare, and milk feeding management in Norwegian dairy herds
}

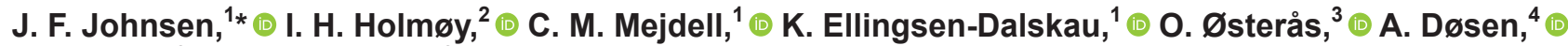 \\ E. Skjerve, ${ }^{2}$ and A. Nødtvedt ${ }^{2}$ (1) \\ ${ }^{1}$ Norwegian Veterinary Institute, Department of Animal Health and Food Safety, PO Box 750 Sentrum, 0106 Oslo, Norway \\ ${ }^{2}$ Norwegian University of Life Sciences, Department of Production Animal Clinical Sciences, PO Box 8146 Dep, 0033 Oslo, Norway \\ ${ }^{3}$ TINE Dairies, Department of Research and Development, Farm Advisory Services, TINE SA, Postbox 58, 1431 Ass, Norway \\ ${ }^{4}$ Norwegian Food Safety Authority, Postbox 383, 2381 Brumunddal, Norway
}

\begin{abstract}
Our aim was to investigate the associations between management factors, compliance with current legislation, and herd-level calf mortality. In a national calf welfare audit, veterinary inspectors from the Norwegian Food Safety Authority assessed compliance with current legislation on calf welfare $(\mathrm{n}=912$ herds). Nine criteria were assessed and rated as satisfactory (1) or not satisfactory (0): housing, natural behavior, single pens, colostrum feeding, feeding, water, surveillance, illness/injuries, and $<5 \%$ mortality rate. In addition, a short questionnaire on milk feeding management for 3-wk-old calves was distributed to all national calf welfare audit herds, and data on mortality and disease recordings were obtained from the Norwegian Dairy Herd Recording System (NDHRS). A herd welfare compliance score (WCS) for each farm was constructed, summarizing the results for the individual criteria. Most herds had a high WCS (median 9.0, range 2-9). Fifty-six percent of the national calf welfare audit herds (508/912) responded to the questionnaire. We performed a cross-sectional study using a data set from 431 herds with available data on recorded disease and mortality events from the NDHRS, recordings from the national calf welfare audit, and the questionnaire. A mixed-effects negative binomial model with Norwegian Food Safety Authority district as the random effect was fitted to the data. Of the 416 herds with available data on calf mortality, 108 (25.9\%) reported no mortality in 2016, and the median 6-mo mortality rate was 0.064 (interquartile range $0-0.11$ ) dead calves per 6 calf-months at risk, based on NDHRS recordings. Calf
\end{abstract}

Received May 8, 2020.

Accepted August 28, 2020.

*Corresponding author: Julie.Johnsen@vetinst.no mortality rates were higher in herds whose calves did not have free access to water (incidence rate ratio 1.29; 95\% confidence interval 1.02-1.64) and higher in herds that had reported calf disease events (incidence rate ratio 1.31; 95\% confidence interval 1.09-1.54). Neither the WCS nor any of the calf milk feeding management factors were associated with mortality, but more than half of producers $(59.6 \%)$ fed less milk than currently recommended for 3 -wk-old calves $(8 \mathrm{~L} / \mathrm{d}$ first 3 to 4 wk). These results indicate that a lack of access to water was associated with higher calf mortality rates. Herds with registered calf disease events had a higher incidence rate ratio of mortality. This finding may be linked to suboptimal calf management, leading to more calf diseases and mortality; or it may be that veterinary consultancy occurs too late or only for the worst cases. There is room for improvement in Norwegian dairy calf management, and water should be provided to young calves.

Key words: observational study, calf health, welfare, regulations

\section{INTRODUCTION}

High calf mortality rates are of concern for animal welfare and contribute to decreased sustainability in dairy production (von Keyserlingk and Weary, 2017). Quantifying calf mortality rates and understanding the underlying risk factors can enable producers and herd health advisors to implement preventive measures.

Known risk factors for perinatal calf mortality include sex (male), being born to primiparous dams, receiving assistance during calving, or being a twin (Cuttance and Laven, 2019). The most recent study in Norway indicated a dairy calf mortality rate from birth to 12 mo of $7.8 \%$ (including stillbirths of $3.4 \%$ and abortion of $0.7 \%$ ), with high between-herd variability (Gulliksen et al., 2009a). It has already been established that common calf diseases such as bronchopneumonia 
and diarrhea are important causes of mortality (e.g., Gulliksen et al., 2009a). Studies in other countries also point to common management practices that increase the health risks of milk-fed calves, such as not using calving pens and having suboptimal routines to ensure colostrum intake (Vasseur et al., 2010).

In Norway, many calf management practices are formulated as minimum standards and defined in legislation (the Animal Welfare Act and the directive under the act on the keeping of cattle; Lovdata, 2004, 2009). As a national governmental body, the Norwegian Food Safety Authority (NFSA) inspects herds for compliance with animal welfare legislation. Inspections in herds classified as high-risk were performed on 1,921 of 15,089 cattle herds (13\%) in 2019 (NFSA, 2020). The NFSA also uses national welfare audits targeting specific focus areas and production forms. Recently, veterinary inspectors from the NFSA visited a representative selection of dairy herds during a national calf welfare audit to better understand compliance with legislation (Døsen, 2016). However, knowledge is lacking about whether compliance with calf welfare legislation is associated with calf mortality rates.

Management procedures related to milk feeding may also be associated with calf mortality (Gulliksen et al., 2009a). Recent advances in research on calf milk feeding management show a positive association between increased milk allowances and calf growth, health, welfare, and productivity (Shamay et al., 2005; RaethKnight et al., 2009; Moallem et al., 2010). Norwegian legislation emphasizes that the feed should "promote good health and welfare, and should be adjusted according to the animals' age, weight, physiological, and behavioral needs" (Lovdata, 2004), but minimum milk allowances for dairy calves are not defined. Advisory services in the Norwegian dairy company TINE recommend feeding $8 \mathrm{~L} / \mathrm{d}$ of milk during the first 3 to 4 weeks (Overrein et al., 2015).

Our aim was to investigate the association between management factors, compliance with current legislation, and herd-level calf mortality rates.

\section{MATERIALS AND METHODS}

\section{Source Population and Study Period}

The source population for this study was herds registered with at least 1 dairy cow in the Norwegian Dairy Herd Recording System (NDHRS). Dairy herd membership in the NDHRS is optional, but 7,745 of 7,928 $(97.8 \%)$ Norwegian dairy herds were registered with the NDHRS in 2018 (TINE, 2018). The study population consisted of dairy herds that were randomly selected to be included in a national calf welfare audit. The focus of the NFSA audit was compliance with current legislation on calf welfare for calves aged 0 to 6 mo. Using the central databases of the NDHRS, $15 \%$ of the herds in each of the 28 NFSA districts (i.e., geographical subdivisions of the NFSA in Norway) were randomly chosen to be included in the national calf welfare audit using a random number generator. The study period was January to December 2016, and all farm visits were carried out between March and December 2016.

\section{Data Sources}

National Calf Welfare Audit. Before the audit, all inspectors took part in a workshop led by the NFSA. The workshop presented recent research and the criteria to be assessed during the audit. The welfare criteria were housing, natural behavior, single pens, maternity pens, colostrum feeding, feeding, water, surveillance, illness or injuries, calf care, and $<5 \%$ mortality (for detailed descriptions, see Supplemental Table S1; https: //doi.org/10.3168/jds.2020-18865). All inspectors also received written guidance on how to evaluate the different criteria based on the relevant legislation. In total, NFSA inspectors visited 912 herds from March to December 2016. The audits were carried out by one or more NFSA veterinary inspectors visiting each farm at a time. In total, 135 NFSA inspectors were involved in the visits. All inspectors were veterinarians affiliated with 1 of the NFSA districts. Audits were notified (i.e., producers were notified $>30$ min before the inspection) or not notified. During the herd visit, each criterion was assigned a rating of "satisfactory" or "not satisfactory" based on legal compliance (Lovdata, 2004, 2009). In cases of "not satisfactory" ratings, inspectors were required to add a comment about their observations that resulted in that rating.

Calf Health Data. Data on counts of calves (0-6 mo) that died or were euthanized in the herd; counts of recorded disease events; days at risk (defined as days the calf was present in the herd); and herd size were obtained from the central databases of the NDHRS (Østerås et al., 2007b). The 6-mo calf mortality pertained to counts of calves that died from the date of expected calving (including stillborn calves) and onwards to the age of 6 mo. In the NDHRS database, each animal has an individual "health card," which follows the individual from birth to slaughter. The information registered on farm is then transferred automatically to the central cattle database. The NDHRS data have been validated for use in epidemiological research for adult cattle (Espetvedt et al., 2013b) and calves (Gulliksen et al., 2009b). A disease event is usually the result of a veterinary visit to a sick calf in the herd. All animal treatments beyond oral rehydration are to be prescribed by a veterinarian, 
Source population: dairy herds randomly selected for the national audit on compliance to current legislation on calf welfare by the Norwegian Food Safety Association (NFSA): 1550 herds

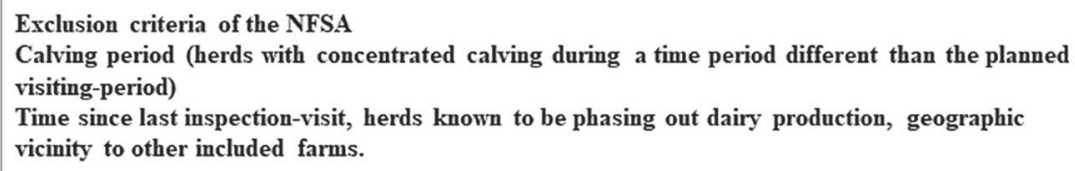

Herds visited by the NFSA: 912

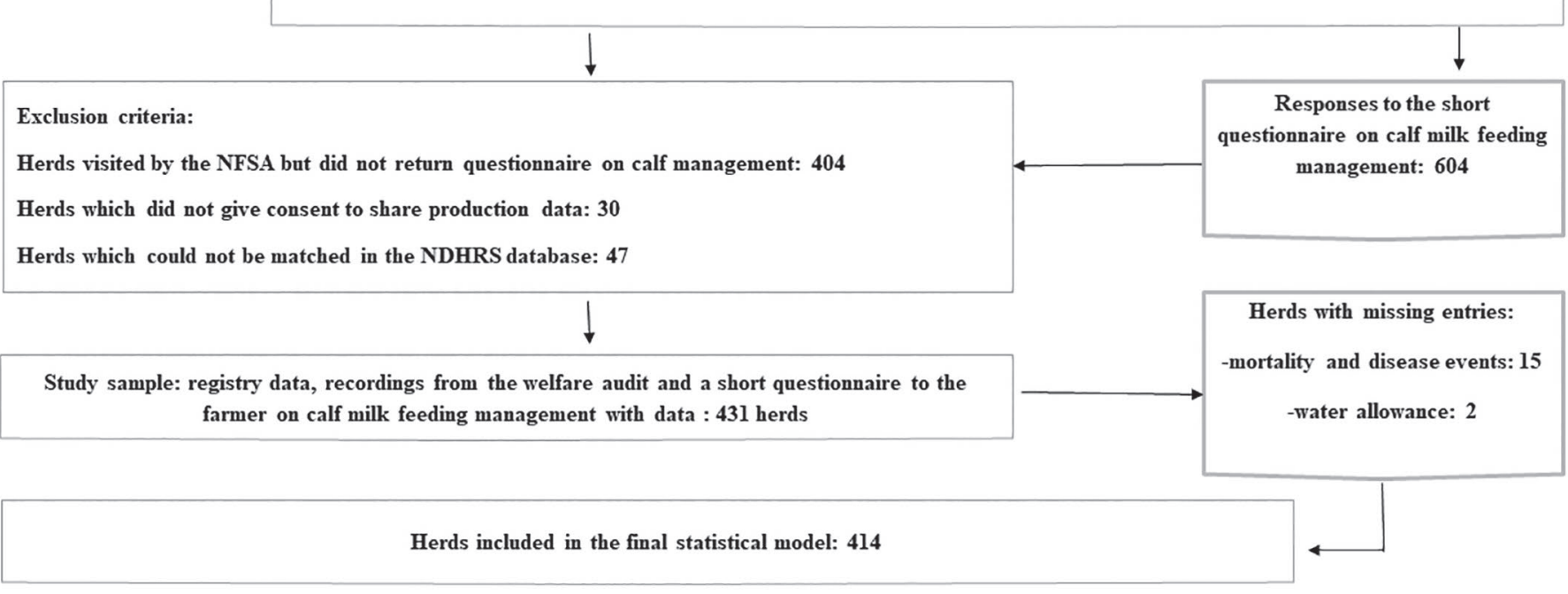

Figure 1. Flowchart of eligible and analyzed herds, and reasons for exclusions in a cross-sectional study of associations between herd-level calf mortality rates, compliance with legislation on calf welfare, and milk feeding management in Norwegian dairy herds.

and prophylactic or metaphylactic antimicrobial agents are not used. Hence, a recorded disease event in most cases represents a clinically affected calf that requires veterinary treatment (Espetvedt et al., 2013b).

Calf Milk Feeding Management Questionnaire. A short questionnaire (Supplemental Figure S1; https: //doi.org/10.3168/jds.2020-18865) on calf milk feeding and management was distributed to each producer by the NFSA inspector(s) during the farm visit. Producers' input into the questionnaire was voluntary. The questionnaires were photographed and returned by mail to the contact person (first author), either by the NFSA inspector or directly by the producer. Producers were asked for their consent to access data from the NDHRS database; in this way, the herd identification number was obtained.

\section{Study Design and Study Sample}

We performed a cross-sectional study combining registry data, recordings from the national calf welfare au- dit, and responses from the producer questionnaire on calf milk feeding management. The final study sample used for statistical analysis of calf mortality consisted of herds with data from all 3 sources. Exclusion criteria are described in Figure 1.

\section{Variables}

Outcome. The outcome of interest was herd 6-mo mortality rate in 2016 , calculated as follows:

Mortality rate $=$

no. of calves that died from expected calving to 6 mo no. of calf days at risk/180

Explanatory Variables. We calculated the disease event rate using the herd count of recorded calf disease events registered for calves less than 6 mo old divided by the calf days at risk per $180 \mathrm{~d}$. For analysis purposes, this variable was dichotomized (registrations 
in the NDHRS of calf disease events in 2016, yes/no). Each new disease event for the same calf was registered as a new observation.

In the national calf welfare audit data, the following welfare criteria were rated as satisfactory (1) or not satisfactory (0): housing, natural behavior, single pens, colostrum feeding, feeding, water, surveillance, illness/injuries, and $<5 \%$ calf mortality. For analysis purposes, the ratings for individual criteria on each farm were summarized into a single score that hereafter will be referred to as the herd welfare compliance score (WCS). We did not include the criterion "surveillance" in the herd WCS because all herds received a score of "satisfactory." Similarly, we assessed the criterion "maternity pens" only in loose-housing barns, because it is not mandatory in tie-stall barns, so we did not include data for this criterion in the analysis. With 9 welfare criteria, the maximum possible herd WCS was 9. The qualitative data on the inspectors' reasoning for assigning "not satisfactory" ratings for a specific criterion were not analyzed. However, the overall comments for each criterion as published in the NFSA report are cited in Table 1 (Døsen, 2016).

\section{Statistical Analysis}

The count of herd calf mortality followed a negative binomial distribution. We investigated the associations between the herd 6-mo calf mortality rate and compliance with legislation on calf welfare and calf milk feeding management using a mixed-effects negative binomial model. We used calf days at risk per $180 \mathrm{~d}$ in each herd in 2016 as the exposure variable in the model. We expected a hierarchical structure in the data due to clustering of geographical locations and NFSA inspectors within NFSA districts. Therefore, we entered NFSA district as a random term. Explanatory variables that were offered to the model were as follows: herd WCS; count of recorded calf disease events in the herd; herd size; daily milk allowance at $3 \mathrm{wk}$ of age $(\mathrm{L} / \mathrm{d})$; daily milk feedings; time housed in single pen (wk); barn type (free stall or tie stall); free access to water at $3 \mathrm{wk}$ (yes/no); use of milk replacer (yes/ no); change of calf milk allowance during recent years (yes/no) and if yes, the previous milk allowance (L/d). Descriptive statistics on potential risk factors related to milk feeding management are presented in Table 2.

We used univariable mixed-effects negative binomial regression for initial screening; variables associated with calf mortality at $P<0.2$ were considered for further analysis. As a second step, we built a mixed multivariable negative binomial regression model using a manual backward stepwise regression strategy until all included variables were significant at $P<0.05$ or they were identified as confounders. Potential confounding variables were identified a priori by constructing a

Table 1. The number and proportion of herds in the study sample with a not satisfactory rating for compliance with current legislation concerning calf welfare ${ }^{1}$

\begin{tabular}{|c|c|c|}
\hline Welfare criterion & $\begin{array}{l}\text { Herds rated } \\
\text { "not satisfactory," } \\
\text { n }(\%)\end{array}$ & Observations leading to the "not satisfactory" rating \\
\hline Housing & $145(33.6)$ & $\begin{array}{l}\text { - No access to a soft, insulated, nonperforated lying surface } \\
\text { - Calves lay directly on slatted wooden floors (single pens), or the group pens were } \\
\text { overcrowded, resulting in calves lying on the slatted floors or in the walking alley }\end{array}$ \\
\hline Natural behavior & $17(3.9)$ & $\begin{array}{l}\text { - Calves were tied on a regular basis or had no social contact with other calves } \\
\text { - Pens were too small to allow natural behaviors }\end{array}$ \\
\hline Colostrum feeding & $12(2.8)$ & $\begin{array}{l}\text { - The colostrum quantity of the first meal reported to the NFSA inspector was considered } \\
\text { too little, or the herd lacked stored colostrum or routines to check colostrum quality }\end{array}$ \\
\hline Feeding & $13(3.0)$ & $\begin{array}{l}\text { - The reported milk allowances were too low } \\
\text { - Calves were considered undernourished. Amounts of roughage were too low, or roughage } \\
\text { was of low quality }\end{array}$ \\
\hline Water & $43(10.0)$ & $\begin{array}{l}\text { - Calves in single pens were not given access to drinking water } \\
\text { - Sick calves had no water access, or access to water nipples with a water capacity that was } \\
\text { too low }\end{array}$ \\
\hline$<5 \%$ mortality & $9(0.02)$ & - Methods to calculate herd calf mortality were not coherent \\
\hline
\end{tabular}

${ }^{1}$ As assessed by inspectors in the Norwegian Food Safety Authority (NFSA) during a national calf welfare audit. Of the 912 herds that were visited in 2016, 431 were included in the study sample.

${ }^{2}$ This welfare criterion was assessed only in loose-housing barns. 
Table 2. Descriptive results on milk feeding management factors studied as potential risk factors for herd calf mortality ${ }^{1}$

\begin{tabular}{|c|c|c|c|c|c|}
\hline Variable & $\mathrm{n}$ & Median & $\mathrm{IQR}^{2}$ & Minimum & Maximum \\
\hline Daily milk feedings for calf age 3 wk (n) & 427 & 3 & $2-3$ & 2 & 10 \\
\hline Missing entries & 2 & & & & \\
\hline \multicolumn{6}{|l|}{ Barn type (cows) } \\
\hline Freestall & 165 & & & & \\
\hline \multicolumn{6}{|l|}{ Free access to water at $3 \mathrm{wk}$} \\
\hline No & 69 & & & & \\
\hline Yes & 360 & & & & \\
\hline Missing entries & 2 & & & & \\
\hline \multicolumn{6}{|l|}{ Use of milk replacer } \\
\hline Yes & 194 & & & & \\
\hline No & 237 & & & & \\
\hline If yes, what was the former milk allowance? & 114 & 6 & $5-6$ & 0 & 9 \\
\hline Missing entries & 2 & & & & \\
\hline
\end{tabular}

${ }^{1}$ A short questionnaire was distributed to the source population of 912 herds visited during a national audit on calf welfare. Of these herds, 508 (56\%) responded and 431 dairy herds constituted the final study population.

${ }^{2}$ Interquartile range.

causal diagram. Variables considered to be potential confounders were tested by running the model with and without the variables in question while exploring changes in estimates. Plausible interactions - established a priori-were also tested. The effect measure was the incidence rate ratio (IRR). We assessed model fit by observing log-likelihood and Akaike information criterion. Many herds had a mortality count of 0 , and a 0-inflated negative binomial regression model was also applied, but it did not improve model fit.

Data handling and statistical analyses were performed in Stata (Stata SE/14; Stata Corp., College Station, TX).

\section{RESULTS}

Figure 1 shows a flowchart of eligible and analyzed herds in the study sample and reasons for exclusion.

\section{Descriptive Statistics}

Among the 416 herds with information on calf mortality, $108(25.9 \%)$ reported no mortality in 2016, and the median 6-mo mortality rate was 0.064 [interquartile range (IQR) 0-0.11] dead calves per 6 calf-months at risk. The median herd size was 21 (IQR 14.8-35.3) cows, and the median herd count of calves that died within the first 6 mo was 2 (IQR 0-3.0; Figure 2).
Among the 416 herds with available data on recorded disease events, $210(50.5 \%)$ reported calf disease events. The most prevalent barn type was tie stall $(61.2 \%)$. The main results of the national calf welfare audit are presented in Table 1. Most of the herds had a high herd WCS, with a median score of 9.0 (IQR 5.1-9.0; range $2.4-9.0)$. Of all herds in the study sample, $285(66 \%)$ were notified before the NFSA visit. Among the loosehousing barns in the study population. NFSA found that calving pens were not satisfactory in 19 (15.1\%) herds.

Out of the 912 herds that NFSA visited during the national calf welfare audit, 508 producers returned the questionnaire (56\% response rate). The regions covered by these respondents $(24,16,32$, and $25 \%)$ were comparable to that of the study population $(21,18,33$, and $27 \%$ from mid- and eastern, northern, southern, and western Norway, respectively). Of the producers in the study sample $(\mathrm{n}=431)$, more than half $(257 ; 59.6 \%)$ reported that calves were fed less than $8 \mathrm{~L} / \mathrm{d}$ at $3 \mathrm{wk}$ of age (Table 2), and milk replacer was used by 194 (45.0\%) producers. Of the producers in the study population, $69(16 \%)$ did not provide their calves with free access to water at the age of $3 \mathrm{wk}$. Of these, $41(9.6 \%)$ also reported feeding $<8 \mathrm{~L} / \mathrm{d}$ of milk to 3 -wk-old calves. Most producers, 285 (66\%) reported that calves were group-housed before the age of $3 \mathrm{wk}$ (median age of group-housing: 2 wk). 


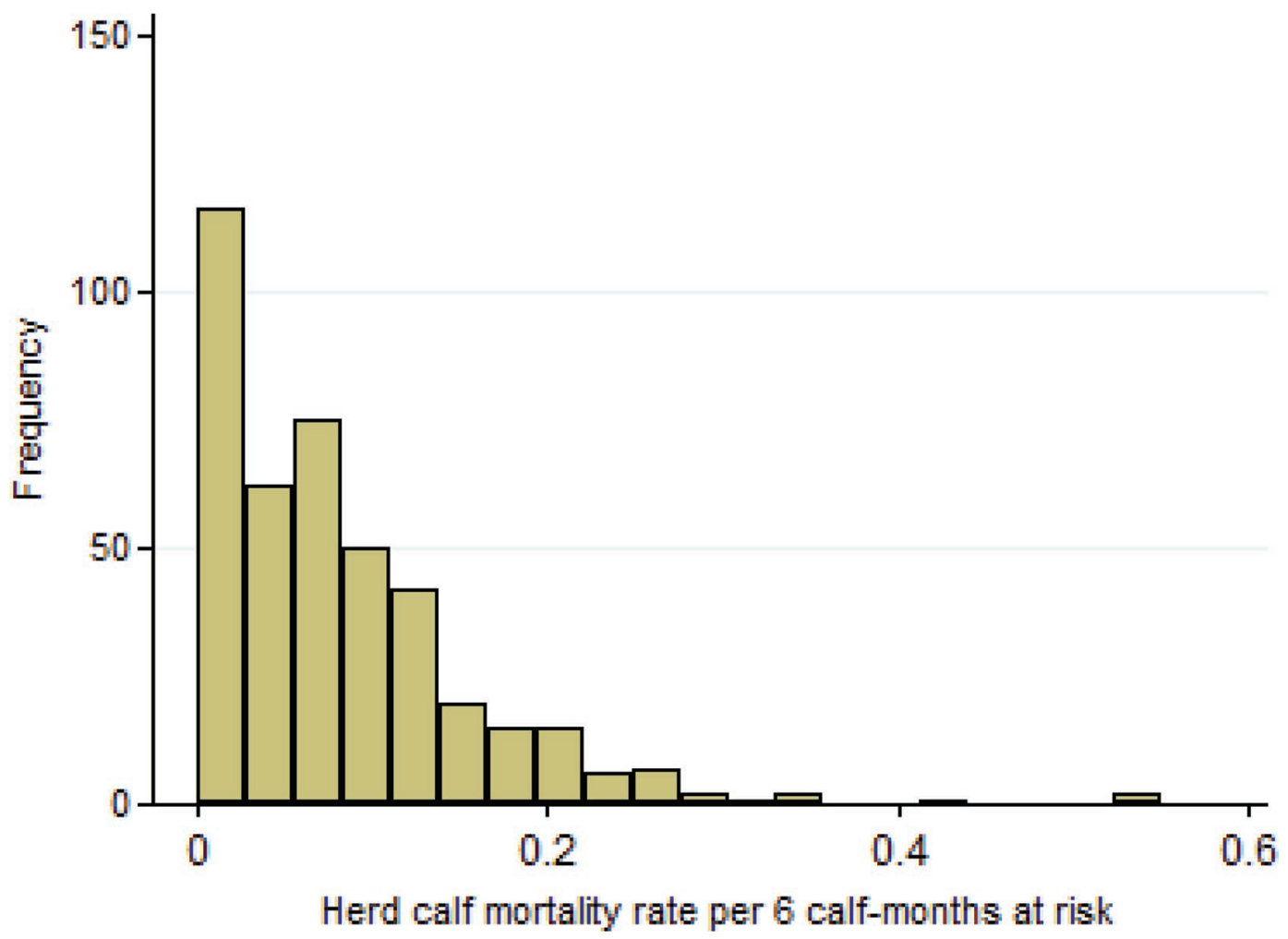

Figure 2. Distribution of herd calf 6-mo mortality rates (i.e., calves that died from birth up to 6 mo of age) among 416 Norwegian dairy herds in a cross-sectional study of associations between herd-level calf mortality, compliance with legislation on calf welfare, and milk feeding management in Norwegian dairy herds.

\section{Statistical Model}

The multivariable model showed that calf mortality rates were higher in herds in which calves had no access to water at 3 wk of age compared to herds in which calves had free access to water (IRR 1.29; 95\% CI: 1.02-1.64; Table 3). Calf mortality was higher in herds that reported calf disease events compared to herds in which no treatments were registered (IRR 1.31; 1.091.54). As a random effect, NFSA district explained none of the unexplained variation in herd calf mortality rates, but it was not removed from the final model. Herd WCS explained variations in calf mortality at the univariable level, but it was not retained in the final model. Except for water access, none of the other calf milk feeding management factors were associated with calf mortality rates.

\section{DISCUSSION}

This study shows that calf mortality from birth to 6 mo varied to a high extent among herds, and many

Table 3. Variables significantly associated with herd counts of calves that died between birth and 6 mo of age ${ }^{1}$

\begin{tabular}{llccc}
\hline Variable & Level & IRR & $95 \%$ CI of IRR & $P$-value \\
\hline Intercept & & 0.06 & $0.05-0.07$ & $<0.001$ \\
Herd calf disease events & No & Referent & - & - \\
Free access to water at $3 \mathrm{wk}$ & Yes & 1.31 & $1.09-1.54$ & 0.003 \\
& Yes & Referent & - & - \\
& No & 1.29 & $1.02-1.64$ & 0.031 \\
\hline
\end{tabular}

${ }^{1} \mathrm{~A}$ mixed effects negative binomial regression model was run using data from 414 dairy herds. Potential risk factors that we investigated were calf herd health data from the Norwegian Dairy Herd Recording System, data on herd compliance to welfare legislation investigated in a national audit by the Norwegian Food Safety Authority, and factors regarding milk feeding management. A random effect of Norwegian Food Safety Authority district was applied to account for intra-district correlation, but $<0.001 \%$ of the variance in 6 -mo calf mortality incidence was explained by the random effect. Results are reported with incidence rate ratio (IRR) and $95 \%$ CI. 
herds $(25.9 \%)$ had no calf deaths. The median mortality rate in this study (0.064 dead calves per 6 calf-months at risk) seemed to be lower than what has been found in other Nordic countries [Nordic Committee for Milk Quality and Østerås et al. (2007a)], but comparable to mortality rate estimates from recent literature reviews (5-8\%, Mee, 2013; 6.2\%, Cuttance and Laven, 2019) and a Norwegian study (7.8\%, Gulliksen et al., 2009a), although the Norwegian study reported calf mortality during the first year of life. However, the lack of a standardized definition for calf mortality renders interstudy comparisons difficult. Our data did not allow us to stratify mortality by calf age, but Gulliksen et al. (2009a) found that stillbirth and abortion accounted for 3.9 and $0.7 \%$ of mortality events, respectively. The design of our study did not allow us to investigate important perinatal risk factors for calf mortality (calf sex, parity, dystocia; Cuttance and Laven, 2019), but these were likely influential.

Herds that reported calf disease events also had greater IRRs of mortality rates. This finding was in line with other studies showing that calves diagnosed with diarrhea, respiratory diseases, or arthritis have an increased risk of death (Waltner-Toews et al., 1986; Svensson et al., 2006; Gulliksen et al., 2009a). This information may provide valuable in risk-based assessment of herd calf welfare, because it may point toward suboptimal management of calves that lead to calf disease and ultimately death. Increased morbidity among calves may also be related to suboptimal colostrum management if they receive inadequate quantities of colostrum, are given colostrum of poor quality, or are ensured colostrum too late after birth (e.g., Weaver et al., 2000). As described for endemic calf diseases as diarrhea (Torsein et al., 2011), producers may contact the veterinarian too late or merely for the worst cases, and this may contribute explanations of the association between veterinary treatment and calf mortality. Calf mortality may also indicate issues concerning cow management and health (Torsein et al., 2014). In herds with calf disease events, re-prioritizing calf health over other issues may be needed (Mee, 2013). In this context, the herd veterinarian may need to state when in the cascade from signs of ill health to death, veterinary help should be sought (Espetvedt et al., 2013a). Underreporting of calf diseases was estimated at approximately $40 \%$ in 2009 (Gulliksen et al., 2009b). Since then, a system for direct veterinary reporting of disease events has been made available, and today the vast majority of disease events (93\%) are reported to the NDHRS directly by the attending veterinarian. We believe that this has reduced underreporting of calf disease events, although the number of herds with no recorded disease events may be artificially deflated. Herd recordings of calf mortality are considered reliable, because it is mandatory to record calf mortality events.

Lack of free access to drinking water at 3 wk of age was associated with calf mortality. By law, Norwegian dairy calves must have free access to water in cases of disease or high temperatures; otherwise, it is not compulsory. Free water intake by calves during the first $16 \mathrm{~d}$ is estimated to be $0.75 \mathrm{~kg} / \mathrm{d}$ (in addition to 6.25 $\mathrm{kg}$ milk/d; Wickramasinghe et al., 2019). Providing free access to water from birth is recognized as an important factor for calf growth and development, potentially by stimulating rumen development (Kertz et al., 1984; Wickramasinghe et al., 2019). Some of the producers $(9.6 \%)$ reported that they fed less milk than is currently recommended and did not provide free access to water, which together may limit fluid intake. The study design did not allow us to conclude whether lack of access to free water caused calf mortality. However, this association with calf mortality rates likely represented a proxy for unmeasured management procedures during the first weeks of the calves' life. The results of the NFSA audit found that lack of water access was primarily an issue for calves housed in single pens (Døsen, 2016). These results indicate that the provision of free access to water should be emphasized in the future.

Herd size was not associated with calf mortality rates in our multivariable model. Previous studies have shown associations between calf mortality rates and herd size (Gulliksen et al., 2009a). Current reports also show that calf mortality rates are higher with increasing herd size (TINE, 2018).

The herd WCS was associated with calf mortality rates only at the univariable level. In the multivariable model, we did not find associations between compliance with current welfare legislation and calf mortality rates. This was probably linked to the fact that the audit focused primarily on legal compliance, which represents the minimum standards. In most herds, the WCS was high, indicating a high level of legal compliance. Although herd calf mortality rates can serve as an indicator of calf welfare (Nyman et al., 2011), less crude measures should reflect all perspectives of animal welfare: biological functioning, natural behavior, and subjective feelings (Fraser et al., 1997). On-farm welfare assessment is a good tool for providing such measures. In a recent Canadian study, good animal welfare, as quantified by the use of the Welfare Quality assessment protocol, was associated with improved productivity and longevity (Villettaz Robichaud et al., 2019). Beyond management and resource-based measures, animal-based welfare indicators bring important extensions to the welfare scoring of dairy herds (Hultgren, 2009). The producer's occupational well-being and low levels of stress have also been shown to have a direct 
positive association with indicators of animal welfare (Hansen and Østerås, 2019).

Surprisingly, milk feeding management factors were not associated with calf mortality rates. Similarly, Gulliksen et al. (2009a) did not find associations between calf milk allowance at the ages of 1 to $4 \mathrm{wk}$ and risk for calf diarrhea. On the other hand, in a study from the United States Jorgensen et al. (2017) found that the higher the peak milk allowance, the lower the odds of a high hind dirtiness score - an indirect measure of diarrhea. According to the audit report, many of the calves in herds that received a "not satisfactory" rating for the feeding welfare criterion were considered malnourished (Døsen, 2016). Lack of water combined with low milk allowances will reduce rather than encourage the intake of solid feed (Kertz et al., 1984).

Our study showed that more than half of dairy producers $(59.6 \%)$ provided young calves with less milk than currently recommended by the Norwegian dairy industry $(8 \mathrm{~L} / \mathrm{d})$. This indicated that restricted milk feeding, which has been practiced since the 1950s (Kertz et al., 1979), is still common. New industry recommendations, including emphasis on a higher daily calf weight gain (700-800 g/d), were published in 2015 (Overrein et al., 2015). Many producers may not be aware of the new guidelines, and this may explain why many producers feed less milk than recommended. Several recent studies have highlighted the importance of providing sufficient milk to the young calf (e.g., Khan et al., 2011; Jorgensen et al., 2017; Rosenberger et al., 2017). Important advantages of feeding higher milk allowances are related to the prevention of hunger (De Paula Vieira et al., 2008), a feeding pattern more consistent with the natural behavior of calves (Appleby et al., 2001), and higher preweaning growth rates (Jasper and Weary, 2002). It is now recommended that calves should be fed higher milk allowances for increased productivity and growth (Geiger et al., 2016; Fischer et al., 2019). In fact, recent meta-analyses have indicated that average daily gain preweaning is positively correlated with first lactational milk yield in adult life (Soberon and Van Amburgh, 2013; Gelsinger et al., 2016). The results of our study indicate that there is considerable room for improvement with respect to calf milk feeding levels.

Limitations to this study are associated with the study design. Using data aggregated at the herd level implies loss of details, and inferences about individual calves may not be deduced from herd-level data. In addition, the questionnaires were completed by producers by self-report, which could have been associated with misinterpretation of questions and recall bias (Coughlin, 1990). Because the welfare criteria were assessed by the individual NFSA inspectors, subjective considerations may have affected the audit (Bracke et al., 1999). However, to align the assessment of the criteria, inspectors received both written and oral guidance before the national calf welfare audit. Because the inspectors were affiliated within a NFSA district, some of the clustering was accounted for in the model. As well, we only know the amount of milk offered to calves at $3 \mathrm{wk}$ of age; producers' routines may have varied throughout the milk feeding period. Because the study design was cross-sectional, our results did not support claims of causality. Norwegian dairy herds are generally small (mean herd size: 28.7 cows) and are declared free of many of the major infectious diseases, including infectious bovine rhinotracheitis and bovine viral diarrhea virus (Hofshagen et al., 2018). These factors may limit the generalizability of the study.

\section{CONCLUSIONS}

Our results indicate a great variation in mortality rates among herds. Many herds had no calf deaths, and a few herds reported many deaths. We found an association between lack of free access to water and higher herd calf mortality rates. Herds that reported calf disease events were associated with greater mortality rates. This may have been related to suboptimal calf management, leading to disease and ultimately death, or it may have been that veterinary consultancy occurred too late or only for the worst cases. More than half of the producers reported feeding less milk than what is currently recommended in Norway. There is room for improvement in Norwegian dairy herds by improving calf management and providing water to young calves.

\section{ACKNOWLEDGMENTS}

The study was funded by the Norwegian research funding for agriculture and the food industry (MATFONDAVTALE; Norwegian Research Council project number 268023). We thank all the veterinary inspectors at the Norwegian Food Safety Authority for their contributions in collecting the questionnaires. We thank Petter Hopp at the Norwegian Veterinary Institute for help with facilitating the random sampling of the source population. The authors thank Ian Dohoo (University of Prince Edward Island, Charlottetown, PEI, Canada) for valuable input on data analysis. The authors have not stated any conflicts of interest.

\section{REFERENCES}

Appleby, M. C., D. M. Weary, and B. Chua. 2001. Performance and feeding behaviour of calves on ad libitum milk from artificial teats. 
Appl. Anim. Behav. Sci. 74:191-201. https://doi.org/10.1016/ S0168-1591(01)00171-X.

Bracke, M. B. M., B. M. Spruijt, and J. H. M. Metz. 1999. Overall animal welfare assessment reviewed. Part 1: Is it possible? Wag. J. Life Sci. 47:279-291.

Coughlin, S. S. 1990. Recall bias in epidemiologic studies. J. Clin. Epidemiol. 43:87-91. https://doi.org/10.1016/0895-4356(90)90060-3.

Cuttance, E., and R. Laven. 2019. Perinatal mortality risk factors in dairy calves. Vet. J. 253:105394. https://doi.org/10.1016/j.tvjl .2019.105394.

De Paula Vieira, A., V. Guesdon, A. M. de Passillé, M. A. G. von Keyserlingk, and D. M. Weary. 2008. Behavioural indicators of hunger in dairy calves. Appl. Anim. Behav. Sci. 109:180-189. https://doi .org/10.1016/j.applanim.2007.03.006.

Døsen, A. 2016. Report on the National Audit on Dairy Calf Welfare. Norwegian Food Safety Authority, Oslo, Norway.

Espetvedt, M., A.-K. Lind, C. Wolff, S. Rintakoski, A.-M. Virtala, and A. Lindberg. 2013a. Nordic dairy farmers' threshold for contacting a veterinarian and consequences for disease recording: Mild clinical mastitis as an example. Prev. Vet. Med. 108:114-124. https://doi .org/10.1016/j.prevetmed.2012.07.014.

Espetvedt, M. N., O. Reksen, S. Rintakoski, and O. Østerås. 2013b. Data quality in the Norwegian dairy herd recording system: Agreement between the national database and disease recording on farm. J. Dairy Sci. 96:2271-2282. https://doi.org/10.3168/jds .2012-6143.

Fischer, A. J., C. Villot, J. K. van Niekerk, T. T. Yohe, D. L. Renaud, and M. A. Steele. 2019. Invited review: Nutritional regulation of gut function in dairy calves: From colostrum to weaning. Appl. Anim. Sci. 35:498-510. https://doi.org/10.15232/aas.2019-01887.

Fraser, D., D. M. Weary, E. A. Pajor, and B. N. Milligan. 1997. A scientific conception of animal welfare that reflects ethical concerns. Anim. Welf. 6:187-205.

Geiger, A. J., C. L. M. Parsons, R. E. James, and R. M. Akers. 2016. Growth, intake, and health of Holstein heifer calves fed an enhanced preweaning diet with or without postweaning exogenous estrogen. J. Dairy Sci. 99:3995-4004. https://doi.org/10.3168/jds 2015-10405.

Gelsinger, S. L., A. J. Heinrichs, and C. M. Jones. 2016. A metaanalysis of the effects of preweaned calf nutrition and growth on first-lactation performance. J. Dairy Sci. 99:6206-6214. https:// doi.org/10.3168/jds.2015-10744.

Gulliksen, S. M., K. I. Lie, T. Loken, and O. Osteras. 2009a. Calf mortality in Norwegian dairy herds. J. Dairy Sci. 92:2782-2795. https: //doi.org/10.3168/jds.2008-1807.

Gulliksen, S. M., K. I. Lie, and O. Osteras. 2009b. Calf health monitoring in Norwegian dairy herds. J. Dairy Sci. 92:1660-1669. https: //doi.org/10.3168/jds.2008-1518.

Hansen, B. G., and O. Østerås. 2019. Farmer welfare and animal welfare: Exploring the relationship between farmer's occupational well-being and stress, farm expansion and animal welfare. Prev. Vet. Med. 170:104741. https://doi.org/10.1016/j.prevetmed.2019 .104741 .

Hofshagen, M., S. Sviland, A. G. Gjevre, and M. Torp. 2018. Report 20b-2017: Surveillance Programmes 2017-Summary of Results. Norwegian Veterinary Institute, Oslo, Norway.

Hultgren, J. 2009. Animal welfare risk assessment and management of risks. Pages 461-482 in Welfare of Production Animals. Vol. 5. F. J. M. Smulders, ed. Wageningen Academic Publishers, Wageningen, the Netherlands.

Jasper, J., and D. M. Weary. 2002. Effects of ad libitum milk intake on dairy calves. J. Dairy Sci. 85:3054-3058. https://doi.org/10.3168/ jds.S0022-0302(02)74391-9.

Jorgensen, M. W., A. Adams-Progar, A. M. de Passillé, J. Rushen, S. M. Godden, H. Chester-Jones, and M. I. Endres. 2017. Factors associated with dairy calf health in automated feeding systems in the Upper Midwest United States. J. Dairy Sci. 100:5675-5686. https: //doi.org/10.3168/jds.2016-12501.

Kertz, A. F., L. R. Prewitt, and J. P. Everett Jr.. 1979. An early weaning calf program: Summarization and review. J. Dairy Sci.
62:1835-1843. https://doi.org/10.3168/jds.S0022-0302(79)83508 $-0$.

Kertz, A. F., L. F. Reutzel, and J. H. Mahoney. 1984. Ad libitum water intake by neonatal calves and its relationship to calf starter intake, weight gain, feces score, and season. J. Dairy Sci. 67:29642969. https://doi.org/10.3168/jds.S0022-0302(84)81660-4.

Khan, M. A., D. M. Weary, and M. A. G. von Keyserlingk. 2011. Invited review: Effects of milk ration on solid feed intake, weaning, and performance in dairy heifers. J. Dairy Sci. 94:1071-1081. https://doi.org/10.3168/jds.2010-3733.

Lovdata. 2004. Forskrift om Hold av Storfe [Directive on the Keeping of Cattle]. Ministry of Agriculture and Food, Oslo, Norway.

Lovdata. 2009. Animal Welfare Act. in LOV-2009-06-19-97. Ministry of Agriculture and Food. Oslo, Norway.

Mee, J. F. 2013. Why do so many calves die on modern dairy farms and what can we do about calf welfare in the future? Animals (Basel) 3:1036-1057. https://doi.org/10.3390/ani3041036.

Moallem, U., D. Werner, H. Lehrer, M. Zachut, L. Livshitz, S. Yakoby, and A. Shamay. 2010. Long-term effects of ad libitum whole milk prior to weaning and prepubertal protein supplementation on skeletal growth rate and first-lactation milk production. J. Dairy Sci. 93:2639-2650. https://doi.org/10.3168/jds.2009-3007.

NFSA (Norwegian Food Safety Authority). 2020. A report from the Norwegian Food Safety Authority on Animal Welfare Inspections Among Terrestrial Animals in 2019. Norwegian Food Safety Authority, Oslo, Norway.

Nyman, A. K., A. Lindberg, and C. H. Sandgren. 2011. Can precollected register data be used to identify dairy herds with good cattle welfare? Acta Vet. Scand. 53(Suppl. 1):S8. https://doi.org/ 10.1186/1751-0147-53-S1-S8.

Østerås, O., M. S. Gjestvang, S. Vatn, and L. Sølverød. 2007a. Perinatal death in production animals in the Nordic countries-Incidence and costs. Acta Vet. Scand. 49(Suppl. 1):S14. https://doi.org/10 .1186/1751-0147-49-S1-S14.

Østerås, O., H. Solbu, A. O. Refsdal, T. Roalkvam, O. Filseth, and A. Minsaas. 2007b. Results and evaluation of thirty years of health recordings in the Norwegian dairy cattle population. J. Dairy Sci. 90:4483-4497. https://doi.org/10.3168/jds.2007-0030.

Overrein, H., A. C. Whist, K. M. Sølvberg, and L. T. Nyhus. 2015. Godt kalveoppdrett- - det er bedre å bygge kalver enn å reparere kyr. T. Rådgiving., ed. TINE rådgivning and medlem, Ås, Norway.

Raeth-Knight, M., H. Chester-Jones, S. Hayes, J. Linn, R. Larson, D. Ziegler, B. Ziegler, and N. Broadwater. 2009. Impact of conventional or intensive milk replacer programs on Holstein heifer performance through six months of age and during first lactation. J. Dairy Sci. 92:799-809. https://doi.org/10.3168/jds.2008-1470.

Rosenberger, K., J. H. C. Costa, H. W. Neave, D. M. Weary, and M. A. G. von Keyserlingk. 2017. The effect of milk allowance on behavior and weight gains in dairy calves. J. Dairy Sci. 100:504-512. https://doi.org/10.3168/jds.2016-11195.

Shamay, A., D. Werner, U. Moallem, H. Barash, and I. Bruckental. 2005. Effect of nursing management and skeletal size at weaning on puberty, skeletal growth rate, and milk production during first lactation of dairy heifers. J. Dairy Sci. 88:1460-1469. https://doi .org/10.3168/jds.S0022-0302(05)72814-9.

Soberon, F., and M. E. Van Amburgh. 2013. Lactation biology symposium: The effect of nutrient intake from milk or milk replacer of preweaned dairy calves on lactation milk yield as adults: a meta-analysis of current data. J. Anim. Sci. 91:706-712. https://doi .org/10.2527/jas.2012-5834.

Svensson, C., A. Linder, and S. O. Olsson. 2006. Mortality in Swedish dairy calves and replacement heifers. J. Dairy Sci. 89:4769-4777. https://doi.org/10.3168/jds.S0022-0302(06)72526-7.

TINE. 2018. Statistics from the Norwegian Dairy Health Recording System. TINE Dairies, ed. TINA Sa, Oslo, Norway.

Torsein, M., M. Jansson-Mörk, A. Lindberg, C. Hallén-Sandgren, and C. Berg. 2014. Associations between calf mortality during days 1 to 90 and herd-level cow and production variables in large Swedish dairy herds. J. Dairy Sci. 97:6613-6621. https://doi.org/10.3168/ jds.2014-7949. 
Torsein, M., A. Lindberg, C. H. Sandgren, K. P. Waller, M. Törnquist, and C. Svensson. 2011. Risk factors for calf mortality in large Swedish dairy herds. Prev. Vet. Med. 99:136-147. https://doi.org/ 10.1016/j.prevetmed.2010.12.001.

Vasseur, E., F. Borderas, R. I. Cue, D. Lefebvre, D. Pellerin, J. Rushen, K. M. Wade, and A. M. de Passille. 2010. A survey of dairy calf management practices in Canada that affect animal welfare. J. Dairy Sci. 93:1307-1316. https://doi.org/10.3168/jds.2009-2429.

Villettaz Robichaud, M., J. Rushen, A. M. de Passillé, E. Vasseur, K. Orsel, and D. Pellerin. 2019. Associations between on-farm animal welfare indicators and productivity and profitability on Canadian dairies: I. On freestall farms. J. Dairy Sci. 102:4341-4351. https:// doi.org/10.3168/jds.2018-14817.

von Keyserlingk, M. A. G., and D. M. Weary. 2017. A 100-year review: Animal welfare in the Journal of Dairy Science - The first 100 years. J. Dairy Sci. 100:10432-10444. https://doi.org/10.3168/jds .2017-13298

Waltner-Toews, D., S. W. Martin, and A. H. Meek. 1986. Dairy calf management, morbidity and mortality in Ontario Holstein herds. III. Association of management with morbidity. Prev. Vet. Med. 4:137-158. https://doi.org/10.1016/0167-5877(86)90019-X.
Weaver, D. M., J. W. Tyler, D. C. VanMetre, D. E. Hostetler, and G. M. Barrington. 2000. Passive transfer of colostral immunoglobulins in calves. J. Vet. Intern. Med. 14:569-577. https://doi.org/10 $.1111 /$ j.1939-1676.2000.tb02278.x.

Wickramasinghe, H. K. J. P., A. J. Kramer, and J. A. D. R. N. Appuhamy. 2019. Drinking water intake of newborn dairy calves and its effects on feed intake, growth performance, health status, and nutrient digestibility. J. Dairy Sci. 102:377-387. https://doi.org/ 10.3168/jds.2018-15579.

\section{ORCIDS}

J. F. Johnsen (ํ) https://orcid.org/0000-0001-5528-9663

I. H. Holmøy @i https://orcid.org/0000-0003-3742-8011

C. M. Mejdell ๑ https://orcid.org/0000-0002-1260-8502

K. Ellingsen-Dalskau ๑ https://orcid.org/0000-0003-1290-2485

O. Østerås @ (ㄴ) https://orcid.org/0000-0002-1292-592X

A. Døsen () https://orcid.org/0000-0002-2566-9283

A. Nødtvedt (1) https://orcid.org/0000-0002-4137-5103 